\title{
AUTORREGULACIÓN DE PUBLICIDAD DE ALIMENTOS Y CONTENIDOS TELEVISIVOS DIRIGIDOS A NIÑOS
}

\section{SELF-REGULATION OF FOOD ADVERTISING AND TELEVISION CONTENT AIMED AT CHILDREN}

Erika Fernández Gómez: Facultad de Ciencias Sociales y de la Comunicación de la Universidad de Vigo (España)

erika.fernandez@uv.es

\section{CURRÍCULUM VITAE}

Docente en el área de Periodismo en la Universidad de Vigo y Doctora docente e investigadora en la Universidad Internacional de La Rioja.

\section{RESUMEN}

En los últimos años han proliferado mecanismos de autorregulación en materia de comunicación, tanto a nivel nacional como europeo, pues se perfilan como uno de los métodos menos costosos y más efectivos para los miembros de las industrias implicadas. Sin embargo, en España a diferencia de lo que sucede en la mayoría de países europeos, no disponemos de una autoridad independiente de regulación de lo audiovisual que vele por su correcto cumplimiento, canalice las demandas de los usuarios y ejerza poder sancionador en su ámbito de actuación. Y por lo tanto, no tienen la misma utilidad para el sector que para los espectadores. 
En este artículo se hace una aproximación a la publicidad de alimentos a la vista del problema actual de obesidad infantil, su difusión a través de un medio de gran influencia (la televisión) y su control a través de los códigos de autorregulación, en los que se recogen las normas de conducta que deben guiar la actuación de los organismos adheridos y que resultan imprescindibles para proteger a un target tan peculiar como son los niños.

\title{
PALABRAS CLAVE
}

Autorregulación - Televisión - Publicidad - Niños - Jóvenes

\begin{abstract}
In the last years, self-regulation mechanisms in communication field have increased. They are one of the least costly methods and more effective for all the members of the implied industries. Nevertheless, they are not so useful for the audience because in Spain we don't have an independent organism that watch over the correct application, canalizes the user's requests and exercise sanctioning power in its area of action.
\end{abstract}

Because of the children's obesity current problem, this article it is an approximation to food advertising. We must take into account the great television influence and the control that self-regulation codes try to carry out. They compile the ethical procedures that must guide the action of the adhered organizations and that turn out to be indispensable to protect a peculiar target like children. 


\section{KEY WORDS}

Self-regulation - Television - Advertising - Children - Young people

\section{ÍNDICE}

1. Introducción

2. Objetivos

3. Metodología

4. Autorregulación de la publicidad de alimentos dirigida a menores: Código PAOS 4.1. Situación actual

5. Autorregulación de contenidos televisivos e infancia

5.1. Contexto actual

6. Aplicación de los códigos de autorregulación a la 2a Cadena de TVE

6.1. Código de Autorregulación de Contenidos Televisivos e Infancia

\subsection{Código PAOS}

7. Conclusiones

8. Bibliografía

9. Notas

\section{TEXTO}

\section{Introducción}

La obesidad infantil es un problema multifactorial que exige una respuesta coordinada de todos los agentes implicados entre los que se incluyen no sólo las 
autoridades sanitarias, padres y educadores, sino también la industria alimentaria, el sector publicitario y los medios de comunicación. En España, según los datos publicados por el Ministerio de Sanidad y Consumo, en el año 2007 la tasa de obesidad se situaba en el 13,9\% de la población infantil y juvenil de entre 2 y 24 años. Las mayores cifras se detectaban en la prepubertad y, en concreto, en el grupo de edad de 6 a 12 años, con una prevalencia del 16,1\%.

En la sociedad de consumo en la que vivimos y caracterizada por el aumento de sobrepeso de los escolares, es necesario que se tomen medidas y se extreme el control sobre la promoción de alimentos, no como única causante del problema pero sí como factor clave a la hora de rectificarlo. Tanto la publicidad como la televisión, en su esencia de fuentes de comunicación, ejercen una gran influencia sobre la educación y el desarrollo social de la infancia.

Los niños representan una de las audiencias más endebles y las cuáles necesitan de una mayor protección. El artículo 20 de la Constitución Española de 1978 reconoce y protege el derecho a la libertad de expresión y difusión de pensamientos, ideas y opiniones, especificando entre otros, el derecho a comunicar o recibir libremente información veraz por cualquier medio de difusión. El ejercicio de estos derechos no puede restringirse mediante ningún tipo de censura previa. Sin embargo, una de sus limitaciones radica en la protección de la juventud y la infancia (ver nota 1).

\section{Objetivos}

Teniendo en cuenta el problema actual de sobrepeso existente entre un gran número de niños en edad escolar y la influencia que la publicidad y la televisión ejercen sobre ellos, los principales objetivos que se persiguen con este estudio son: 
Analizar el contexto actual de la publicidad de alimentos dirigida a menores y su difusión a través de la televisión.

Determinar la relación existente entre publicidad de alimentos y obesidad infantil. ¿Se están tomando medidas al respecto?

Explorar el marco legal y los códigos de autorregulación existentes en materia publicitaria y audiovisual en relación a la infancia. ¿Los agentes implicados cumplen las normas?

Hacer una aproximación empírica al panorama televisivo de hoy en día desde el punto de vista de la programación y la publicidad dirigida al público juvenil e infantil. Y para ello, analizar los contenidos de la $2^{\text {a }}$ Cadena de TVE que, como cadena pública tiene una serie de principios y obligaciones que ha de respetar y además, es uno de los canales generalistas españoles con mayor número de contenidos infantiles y juveniles.

\section{Metodología}

Para llevar a cabo este estudio y tratar de dar respuesta a las preguntas anteriores, se ha empleado la siguiente metodología:

Estudio de las parrillas de programación de las principales cadenas generalistas del mercado televisivo español (TVE-1, La 2, Antena 3, Telecinco, Cuatro y La Sexta). Para ello se han tomado como referencia dos muestras, una referida a los contenidos emitidos en 2007 (del lunes 11 al domingo 17 de junio de 2007) y la otra, a 2008 (del lunes 28 de abril al domingo 4 de mayo de 2008).

Visionado de grabaciones de archivo de los programas emitidos por La 2. Se ha seleccionado como muestra representativa los programas infantiles emitidos por la cadena el miércoles 30 de abril de 2008.

Análisis de distintos códigos y normativas: Código PAOS (Código de Autorregulación de la Publicidad de Alimentos dirigida a menores, prevención de 
obesidad y salud), Acuerdo FIAB (Federación de Industrias de Alimentación y Bebidas), Directiva Europea de Televisión Sin Fronteras (DTVSF) y el Código de Autorregulación sobre Contenidos Televisivos e Infancia.

\section{Autorregulación de la publicidad de alimentos dirigida a menores: Código PAOS}

"La obesidad es una enfermedad de carácter crónico y de origen multifuncional que se ha convertido en uno de los problemas de Salud Pública más preocupantes de nuestro país (...). La obesidad es el resultado de un incorrecto equilibrio entre ingesta/ gasto, por lo que tanto la actividad física como las pautas alimentarias deben ser consideradas" (ver nota 2 ).

A través del Código de Autorregulación de la Publicidad de Alimentos dirigida a menores, prevención de la obesidad y salud (Código PAOS) promovido por la Federación de Industrias de Alimentación y Bebidas (FIAB), que entró en vigor el 15 de septiembre de 2005, se regula la publicidad de todos los alimentos y bebidas dirigidos a menores, especialmente, la destinada a los niños de hasta 12 años y que se difunde a través de cualquier medio o soporte (ver nota 3).

En el Código se resalta que el sedentarismo y el déficit de gasto energético, provocados por las nuevas pautas y hábitos de conducta de nuestra sociedad moderna, juegan un papel principal en el aumento de la obesidad y el sobrepeso. De este modo, no cabe responsabilizar del problema a la industria española de alimentación y bebidas ni a productos alimenticios concretos o su publicidad. En todo caso, la Federación de Industrias de Alimentación y Bebidas concienciada con el problema, se ha comprometido a jugar un papel constructivo y proactivo en esta compleja tarea colectiva contra la obesidad, estableciendo altos niveles de 
responsabilidad social en sus actividades publicitarias, especialmente en las dirigidas a los niños.

El objetivo principal del Código PAOS es establecer un conjunto de reglas que guíen a las compañías adheridas en el desarrollo, ejecución y difusión de sus mensajes dirigidos a menores. Se persigue evitar una excesiva presión publicitaria sobre ellos y contribuir a fomentar entre la población infantil y juvenil hábitos saludables de alimentación y la práctica de ejercicio físico.

El Código rige a aquellas empresas adheridas al acuerdo, unas 36 compañías del sector que representan más del $70 \%$ de la inversión, y no atañe al etiquetado y embalaje de los productos, el cuál es limitado por una legislación específica. El Jurado de la Publicidad de Autocontrol (Asociación para la Autorregulación de la Comunicación Comercial) es el organismo encargado de controlar su cumplimiento y es el que se encarga de resolver las eventuales reclamaciones que se presenten por infracción de las normas fijadas, en relación a la publicidad de las empresas aglutinadas.

Además de esta regulación específica sobre publicidad de alimentos dirigida a menores, la promoción del sector de alimentación está sujeta a un numeroso conjunto de normas comunitarias, nacionales e incluso autonómicas además de a la legislación general de publicidad, a la normativa reguladora de los distintos medios y soportes en cuanto a vehículos de difusión publicitaria y a las legislaciones concernientes a esta industria como, por ejemplo, las de embalaje y etiquetado.

La última Directiva Europea sobre el ejercicio de actividades de radiodifusión televisiva del año 2007 (ver nota 4), también recoge la importancia de cuidar que la 
comunicación comercial no fomente hábitos alimenticios inapropiados en relación al público infantil y juvenil:

"Los Estados miembros y la Comisión impulsarán a los prestadores del servicio de comunicación a desarrollar códigos de conducta en relación con la comunicación comercial audiovisual inadecuada que acompañe a los programas infantiles o se incluya en ellos, de alimentos y bebidas que contengan nutrientes y sustancias con un efecto nutricional o fisiológico, en particular aquellos tales como grasas, ácidos transgrasos, sal o sodio y azúcares, para los que no es recomendable una ingesta excesiva en la dieta total" (ver nota 5)

En esta Directiva también se limita la cantidad de anuncios que se pueden emitir en relación al tipo de programación y público objetivo de la misma. En general, la proporción de anuncios de publicidad y de televenta no pueden exceder del $20 \%$ de la programación por hora de reloj. Un máximo de 12 minutos de publicidad en cada hora de programación. Asimismo, la retransmisión de programas infantiles podrá ser interrumpida una vez por cada período previsto de treinta minutos como mínimo, siempre y cuando la duración prevista del programa sea superior a treinta minutos (ver nota 6).

\subsection{Situación actual}

Con la finalidad de asegurar la adecuación de la publicidad al Código de autorregulación PAOS, existe un compromiso por parte de las empresas adheridas al mismo de enviar al Gabinete Técnico de Autocontrol, para su examen antes de su emisión a través del sistema de consulta previa o Copy Advice, todos los anuncios de alimentos y bebidas dirigidos a menores de 12 años así como los anuncios televisivos cuya emisión vaya a llevarse a cabo en las franjas horarias de protección reforzada de 
la infancia (fijadas en el Código de Autorregulación sobre Contenidos Televisivos e Infancia) (ver nota 7).

En el año 2007, Autocontrol supervisó antes de su emisión el 90\% de la publicidad dirigida a niños. Lo cual, demuestra una mayor preocupación e implicación por parte de anunciantes, agencias y medios de comunicación en cuanto a protección de los menores (ver nota 8). Parece que el principio de responsabilidad social comienza a estar presente en la comunicación comercial de los anunciantes ya que, el Jurado de la asociación sólo ha desaconsejado la difusión del anuncio en un 3,7\% de los casos. En total, sólo se recogieron 3 reclamaciones sobre publicidad dirigida a menores. El mayor número de proyectos que la asociación recibió para su revisión se referían a publicidad de juguetes, seguida de publicidad de bebidas alcohólicas y en tercer lugar, a publicidad de alimentos dirigida a niños. Y por medios, el mayor número de peticiones de consulta previa se refería a proyectos de anuncios en televisión.

La asociación para la autorregulación publicitaria atendió en 2007 un $21 \%$ de reclamaciones más que en el año 2006. Sin embargo, también aumentó el número de solicitudes de asesoramiento, como medida preventiva antes de la emisión de la publicidad. Esto se debe a la campaña que Autocontrol lanzó el año anterior y que generó un mayor conocimiento por parte de los consumidores de la existencia de este organismo y en consecuencia, un mayor uso del mismo (ver nota 9). Además, el mayor número de consultas previas se ha referido precisamente a protección de menores, lo cuál parece demostrar que el sector está empezando a concienciarse sobre la importancia de proteger a este público con unas características especiales.

Como encargada de realizar el seguimiento del cumplimiento del Código PAOS, Autocontrol revisó el pasado año 2007 un total de 394 proyectos de anuncios sobre publicidad de alimentos y/o bebidas dirigida a menores (ver nota 10). De los 
proyectos de anuncios analizados, 288 obtuvieron un Copy Advice positivo, en 84 ocasiones se recomendó la modificación del proyecto de anuncio y se recomendó la no emisión de 22 proyectos de anuncio. La mayor parte de los proyectos presentados correspondían al medio televisión (388), los 6 restantes eran proyectos de anuncios para el medio Internet. Todos los proyectos de anuncios que recibieron alguna recomendación de modificación u observación fueron corregidos antes de su emisión.

Desde la entrada en vigor del Código PAOS, el Gabinete Técnico de AUTOCONTROL recibió 976 consultas previas sobre proyectos de anuncios de alimentos y bebidas dirigidos a niños por parte de empresas adheridas a PAOS. Por lo que se observa un significativo cambio ya que cada vez son más los anunciantes que envían sus proyectos de anuncio, ya sea directamente o a través de su agencia, antes de su realización, con el objetivo de evitar errores en las primeras etapas de desarrollo de la campaña y cuya solución se hace más complicada y costosa en fases posteriores.

El funcionamiento de Código y del sistema implantado por Autocontrol parece estar siendo bastante eficaz. En 2006 se produjeron 9 reclamaciones ante el Jurado de Publicidad por presunta infracción de las normas de conducta en él recogidas mientras que, en 2007, la reducción ha sido muy significativa, tan sólo se registró una reclamación. A la vista de los resultados, parece que las distintas empresas han asumido de forma generalizada el Código PAOS, al haber adecuado sus campañas al mismo. 


\section{Autorregulación de contenidos televisivos e infancia}

Como se ha podido ver en el apartado anterior, la publicidad dirigida a niños a través de la televisión es de la que más se solicita una consulta previa antes de su emisión. En las nuevas generaciones la influencia de la pequeña pantalla en su formación ha ido acrecentándose. Las nuevas formas de vida en las que la falta de tiempo de los padres e incluso el tipo de entorno (grandes ciudades donde existen ciertos peligros para un niño) tiene como consecuencia que el menor se quede en casa y encienda el televisor (ver nota 11).

La televisión es un medio que fascina a los niños. Durante los primeros años, el niño está fuertemente influido por su contexto ya que no tiene competencia cognitiva y por ello, valora los hechos más por la fuente de donde proceden que por su significado. Por eso, se hace necesario controlar los contenidos televisivos que son susceptibles de ser consumidos por el público infantil además de un evidente control paterno.

Asimismo, la publicidad a través de este medio les proporciona conocimientos sobre el mundo en el que viven. Es importante que los mensajes publicitarios difundidos a través de la televisión sean verdaderos pues, por sus propias características (combinación de imagen y sonido) es el medio más proclive a ser consumido por los más pequeños, los cuáles no tienen la capacidad suficiente para valorar la información transmitida de manera objetiva.

Existen diversas normativas, tanto en el ámbito nacional como en el europeo, que regulan las actividades de radiodifusión televisiva y que velan por los intereses de este segmento de la población. En España, la Ley de Radio y Televisión Estatal (ver nota 12) recoge que la programación del servicio público que se le ha encomendado 
que atañe a la Corporación RTVE deber atender especialmente a los colectivos sociales que requieran una atención específica hacia sus necesidades y demandas, como son la infancia y la juventud.

La autorregulación en materia de programación televisiva es una exigencia que viene reiterándose desde hace tiempo por las instituciones comunitarias. En el año 2000, el propio Parlamento Europeo declaró como urgente el que todos los operadores televisivos europeos fijasen un código de autorregulación en materia de protección de menores que contuviera mecanismos de control social y cláusulas severas de sanción en caso de incumplimiento. En ese contexto surgió el Código de Autorregulación sobre Contenidos Televisivos e Infancia (ver nota 13).

El Gobierno urgió a las cadenas a firmar un código de autorregulación que entró en vigor el 9 de Marzo de 2005. Previamente, el 9 de diciembre de 2004, fue suscrito por Telecinco, Antena 3, Sogecable (Cuatro y Canal+) y TVE, sumándose a él, posteriormente, La Sexta, los operadores de TDT, Veo TV y Net TV, así como las diferentes televisiones autonómicas a través de FORTA.

La Directiva de Televisión Sin Fronteras (DTVSF) había fijado un horario de protección del menor entre las 6.00 y las 22.00 horas. Con el nuevo reglamento se establecen unas franjas de protección reforzada para el público que se considera más vulnerable, el infantil y que estaría compuesto por los menores de 13 años.

Los bloques horarios especiales que establece son: de 8.00 a 9.00 y de 17.00 a 20.00 horas (de lunes a viernes) y de 9.00 a 12.00 horas (sábados, domingos y festivos). El objetivo de estas nuevas franjas es mejorar la protección legal de los niños respecto de la programación televisiva que se emita en dicho horario. Además, las televisiones firmantes del Código, conscientes de la especial incidencia del público infantil 
durante las vacaciones escolares, han expresado su intención de mostrar una especial sensibilidad a ese hecho a la hora de elaborar la programación televisiva.

\subsection{Contexto actual}

Según el Estudio General de Medios correspondiente al período comprendido entre abril de 2007 y marzo de 2008, la televisión sigue siendo el medio líder en audiencia con una penetración del 88,8\%. Un total de 33.979 espectadores diarios y un consumo de 221 minutos por persona y día. Los niños de entre 4 y 12 años consumen un total de 140 minutos diarios de televisión (ver nota 14).

Casi todas las cadenas generalistas incumplen la medida diaria de protección reforzada de la infancia en horario de tarde (de 17.00 horas a 20.00 horas). Según el Segundo Informe de Evaluación sobre la Aplicación del Código de Autorregulación de Contenidos Televisivos e Infancia llevado a cabo por la Comisión Mixta de Seguimiento durante su segundo año de vigencia (marzo 2006-marzo 2007), se produjeron 359 reclamaciones frente a las 120 recogidas en 2006 (ver nota 15). El mayor número de reclamaciones registradas se referían a la programación de Antena 3 (209), seguida de Cuatro (71), Telecinco (46), La Sexta (18) y TVE 1 (15). Del conjunto de quejas contabilizadas se aceptaron 31 de ellas: 12 de Antena 3 y Cuatro, 4 de Telecinco, 2 de La Sexta y 1 de TVE.

Precisamente, el programa más conflictivo sobre el cuál Antena 3 recibió mayor número quejas fue Shin Chan con un total de 121 peticiones. Esta serie japonesa es consumida preferentemente por niños pero, a pesar de ser dibujos animados, su contenido no es apropiado para el público infantil ya que transmite una imagen machista, emplea un lenguaje verbal inapropiado y el comportamiento del protagonista (un niño de cinco años) no es el más adecuado. 
Durante el 2007, Shin Chan se programó de lunes a viernes en la franja de protección reforzada matinal, es decir, de 8 a 9 de la mañana. En el 2008, se emitió sólo los fines de semana a partir de las 13.00 horas, horario que ya no se considera de protección especial de la infancia. Sin embargo, aunque se ha dejado de ofrecer en la oferta semanal de la cadena generalista, se programó en el canal digital que dedica al público juvenil (Antena Neox) y en el mismo horario de protección reforzada de la infancia (8 de la mañana). A pesar de la temática conflictiva de esta animación, pues tiene una calificación como no recomendada para menores de 7 años, en las franjas de protección reforzada sí se puede emitir ya que, el Código sólo especifica que en estos bloques horarios no se programarán espacios no recomendados para los menores de 13 años. Motivo por el cuál, las quejas que fueron presentadas ante el Comité de Autorregulación no han sido aceptadas.

En relación a las reclamaciones recogidas sobre programas emitidos en franja legal de protección del menor, pero fuera de la franja de protección reforzada, han sido significativas las referidas al espacio Padre de Familia que emite La Sexta en la franja de mediodía (15.00 a 15.30), todos los días de la semana. Se trata de un espacio que, al igual que Shin Chan, es consumido sobre todo por niños y jóvenes, pero que su contenido (referencias sexuales) y lenguaje (basados en la ironía y el sarcasmo) hacen de el un producto no apto para la infancia. De hecho, está calificado como para mayores de 13 años. Aunque los niños no puedan entender muchas de las conversaciones, son atraídos por el colorido de las imágenes y les causan gracia sus protagonistas, los cuáles no tiene un comportamiento favorable. Por lo que debe tenerse en claro que los dibujos animados no son sinónimo de contenido infantil, ya que existen numerosos formatos dirigidos a un público adulto.

Además de estos espacios, programas como Aquí hay tomate (Telecinco) o Libertad Vigilada (Antena 3) que se emiten en horario vespertino también han sido objeto de 
crítica. La mayor parte de las cadenas generalistas emiten durante el horario protegido programas que no son apropiados ni para el público infantil ni para el juvenil. Sólo con observar a la parrilla de programación que las distintas cadenas presentaban en el año 2007, así como las que tenían en 2008, basta para poder concluir que los niños y los jóvenes constituyen el target más olvidado del panorama televisivo actual.

Tanto Los Simpson como Padre de Familia son series animadas no recomendableas para el público infantil pero, que han tenido una gran audiencia en Estados Unidos y que en nuestro país se sitúan en los horarios de mayor audiencia. Así, Los Simpson se emiten en Antena 3 en la franja de acceso a mediodía (de 14.00 a 15.00 horas) y en Antena Neox en prime time (de 21.00 a 22.00 horas). Y Padre de Familia se emite en la franja de mediodía (de 15.00 a 15.30 horas).

Por otro lado, en cuanto a publicidad televisiva, la Directiva comunitaria de Televisión Sin Fronteras (DTVSF) fue revisada en 2006 pero, en vez de haber tenido como objeto recortar y controlar la emisión máxima de anuncios y dar respuesta así a las demandas de los consumidores, se ha cedido ante intereses comerciales (ver nota 16). La nueva normativa ha eliminado el tope máximo de tres horas de publicidad al día y ha mantenido los 12 minutos por cada hora, lo que supone que en las 24 horas que tiene el día, se pueden emitir un total de 288 minutos, 4.8 horas diarias de publicidad. Así, en detrimento de los espectadores y sobre todo, de los niños, se ha liberalizado la publicidad hasta casi cinco horas diarias de emisión. Además, se han mantenido los 30 minutos durante los cuales la programación infantil no puede ser interrumpida por publicidad.

Destaca lo sucedido en el Reino Unido pues, se han prohibido los anuncios de comida basura en horario infantil dado el desastre alimenticio que se está 
produciendo actualmente entre los niños (ver nota 17). Los ingleses han prohibido la emisión de aquellos anuncios de "comida basura" en cualquier programa y a cualquier hora del día en que la mayoría de los televidentes sean menores de 16 años. Lo cual, refleja la gran diferencia entre la situación respecto a nuestro país donde, además de que se sigue promocionando este tipo de productos, la mayor protección recae en los menores de 12 años. Mientras que los británicos han elevado las medidas protectoras a jóvenes de hasta 16 años.

\section{Aplicación de los códigos de autorregulación a la $2^{\mathrm{a}}$ Cadena de TVE}

Tras haber hecho una aproximación a la situación de la publicidad de alimentos dirigida a niños, teniendo en cuenta los alto índices de obesidad infantil, su difusión a través del medio líder en nuestro país, así como las normativas sobre programación infantil y publicidad que a esta le atañen, en este apartado se valora el escenario actual de una de las cadenas generalistas con menor presencia entre las demandas por incumplimiento de las normativas, la $2^{\text {a }}$ Cadena de TVE.

\subsection{Código de Autorregulación de Contenidos Televisivos e Infancia}

Como se ha comentado, a lo largo del año 2007 la mayoría de las cadenas generalistas de nuestro país destacaron "por la falta de tacto" durante los horarios infantiles ya que en sus parrillas de programación sobresalieron los contenidos inadecuados para el público infantil. Si comparamos la parrilla de programación de las principales cadenas de nuestro país a mediados de los 90 con la programación actual, podemos encontrar diferencias considerables. La franja habitual dedicada a los niños fue muy competitiva al comienzo de las televisiones privadas, sin embargo, hoy ha desaparecido casi por completo (Cortés, 2001: 127). 
En la tabla 1 que se adjunta, se puede observar la parrilla de programación de una de las cadenas de televisión generalistas más importantes de nuestro país y la privada más longeva, Antena 3. Las franjas sombreadas señalan aquellos contenidos que en 1996 estaban destinados principalmente a un público infantil (menores de 13 años) y juvenil (de 13 años en adelante) (ver nota 18). Así, el Club Megratrix se emitía todos los días de la semana, de lunes a domingo, y contenía numerosas producciones animadas con las que los niños podían disfrutar.

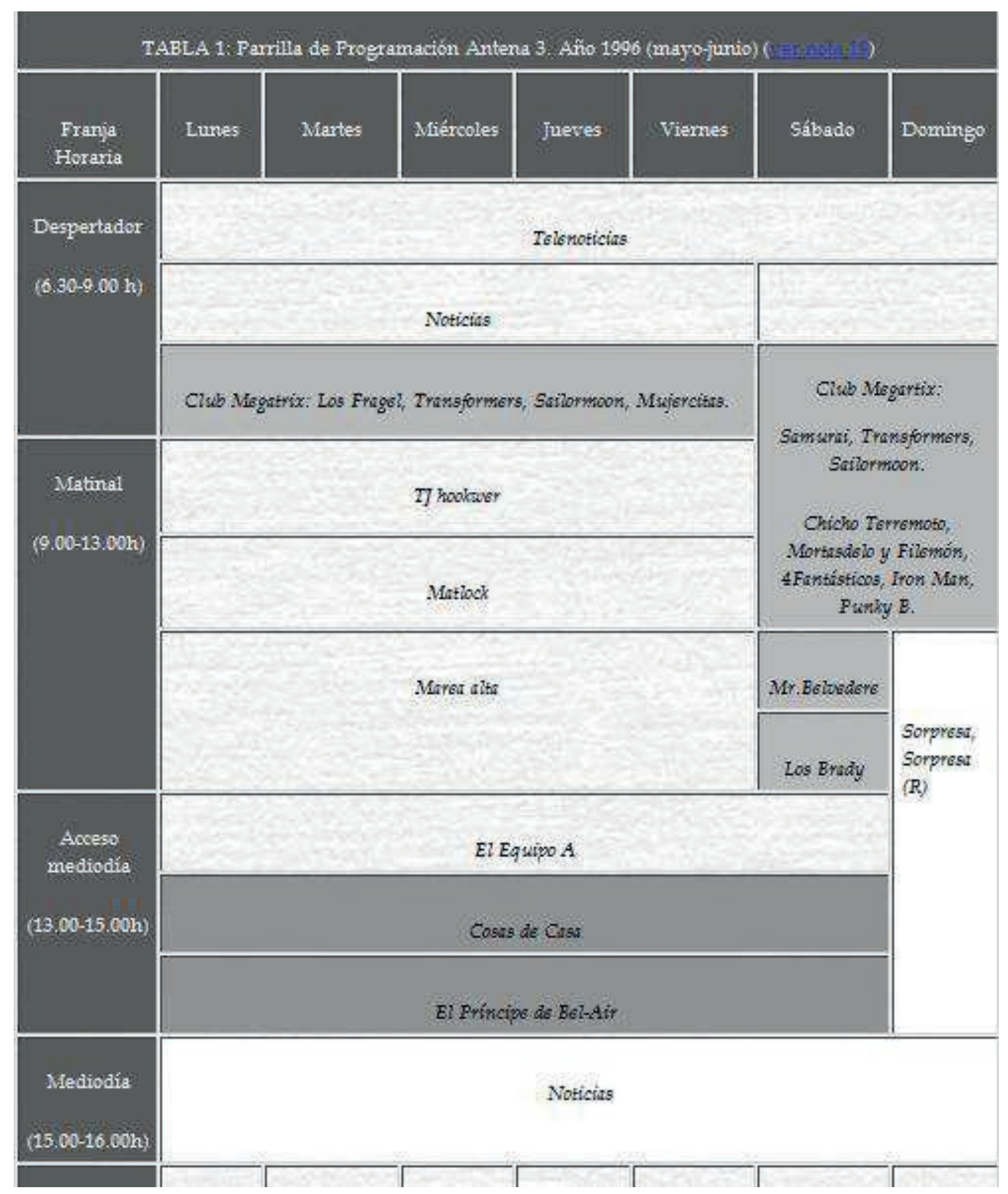


Al observar la programación de la misma cadena doce años después, en 2008(véase tabla 2), se aprecia una considerable disminución de los contenidos destinados a un público infantil y juvenil. La emisión de espacios dirigidos a niños se ha reducido a la franja matinal de los fines de semana. Los dibujos y series se han substituido por informativos destinados a un público adulto. Además, casi todos los programas que componen el contenedor Megatrix son series, a excepción del espacio de manualidades Art Attack y Shin Chan.

De lunes a viernes, la única animación que emite esta cadena son Los Simpson, que al igual que sucede con los dibujos japoneses Shin Chan, no son apropiados para la infancia. A pesar de ser una de las series más veteranas de la televisión estadounidense y también española (comenzó en 1989), cuenta con varios niveles de comprensión. El lenguaje empleado y las críticas políticas y sociales realizadas a la sociedad americana hacen de la serie una producción orientada al público adulto.

Todo esto tiene como consecuencia que niños y jóvenes busquen una alternativa mejor en otros medios a través de la cuál satisfacer sus necesidades (Internet). Además del consumo de productos inapropiados para su edad. 


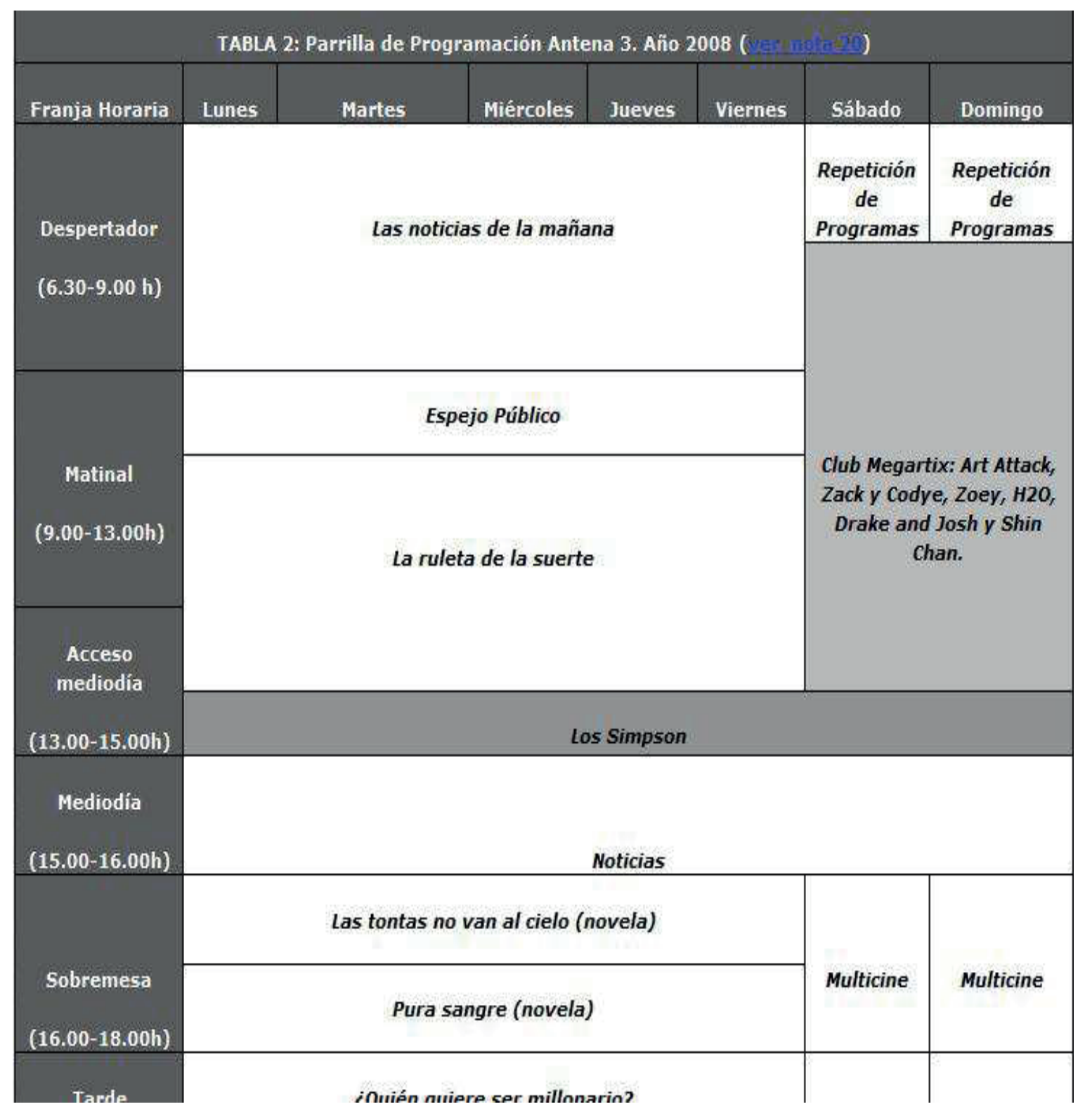

Durante el año 2007, La 2 fue la única cadena generalista que en su programación de primavera de lunes a viernes, durante la franja de acceso a mediodía (de 13.00 a 15.00 horas), programó espacios apropiados para un público infantil.

Como ya se ha reiterado, Los Simpsons se dirigen más bien al público adulto y también juvenil (ver nota 21). 
Así, a la hora de la comida los niños podían disfrutar de tres series de animación que se emitían en el segundo canal de TVE: La leyenda del dragón, Iron Kid y Las tortugas Ninja. Por el contrario, las demás cadenas en esta franja horaria programaban contenidos destinados a un público adulto, especialmente informativos. Lo mismo sucedía en la franja de la tarde ya que, mientras las demás cadenas de televisión emitían telenovelas, magazines y concursos, La 2 programaba espacios dedicados a una audiencia infantil como el programa de divulgación científica Leonart y también contenidos dirigidos a los jóvenes como las series Blue Water High y Lois \& Clark: las nuevas aventuras de Superman.

Esta característica programación del segundo canal durante el año 2007 nacía como consecuencia de la nueva estrategia que el director de TVE, Javier Pons, había anunciado ya a principios de la temporada bajo el lema La 2 se mueve. Era un proyecto ambicioso que pretendía dotar de competitividad a la segunda cadena para que dejara así de ser "para una inmensa minoría" y que sobre todo perseguía acercar La 2 al público joven y ofrecer una propuesta distinta y complementaria de La Primera. En este sentido, los cambios que la $2^{\mathrm{a}}$ Cadena de TVE proponía eran trascendentales no sólo en cuanto a imagen o programación sino, en la forma en la que esta cadena de ámbito público pretendía posicionarse, ya que pretendía dirigirse a un target que, como se ha visto, no tiene su sitio en la oferta televisiva de hoy en día. A pesar de las reclamaciones realizadas por los espectadores respecto al incumplimiento del horario protegido, la situación en 2008 no sufrió variaciones. Es decir, en las franjas de especial protección de la infancia sólo La 2 destacó por ofrecer espacios destinados a este target. En la primera hora de protección que comprende desde las 8 a las 9 de la mañana, Antena 3, TVE y Telecinco emitieron el informativo matinal. La Sexta programó la emisión de los dibujos animados Yuku Hakusho a las 8 de la mañana pero, a las 8.25 horas, todavía en horario de protección reforzada, emitió el comercial de Teletienda hasta las 9 (infringiendo en código en esa última 
media hora). En el caso de Cuatro el incumplimiento fue tan sólo de diez minutos pues, a las 7 de la mañana emitió el espacio infantil Los Algos y a las 8.50 comenzó El zapping de los Surferos.

En el caso de La 2, el tiempo destinado en la franja despertador a los niños fue superior al destinado por La Sexta y Cuatro. Además de que los contenidos emitidos eran de producción propia y contenían elementos educativos. Así, de lunes a viernes, la segunda cadena pública emitió a las 7 horas el espacio divulgativo de la ciencia Leonart. Media hora ofreció el contenedor Los Lunnis que incluía varias series especialmente recomendadas para los niños preescolares por sus contenidos pedagógicos: Clifford, el gran perro rojo; Caillou; Pocoyó y Alex y Alexis (véase tabla 3).

La 2 programó un total de dos horas y media diarias durante todos los días de la semana por lo que, el compromiso de la cadena con este segmento de la población difiere en gran medida del presentado por la competencia. Además, la conducta responsable hacia esta audiencia se reflejó durante todas las franjas de protección especial de la infancia.

En la banda horaria de acceso a mediodía, al igual que en el año 2007, continuó siendo la única cadena generalista en destinar ese horario a programar contenidos para el público infantil. Aunque a esta franja no le concierne la normativa de máxima protección sigue estando dentro de las horas de protección del menor (de 6.00 a 22.00 horas). Desde las 13.30 a las 15.30 horas, emitió el contenedor Comecaminos, destinado a niños de entre 8 y 12 años y que incluye las series: Lo que me gusta de ti y Locos por la Ciencia. 
En la franja de la tarde, desde las 18.00 a las 20.30 horas, el segundo canal de TVE emitió el contenedor En Construcción. En este caso, a pesar de que el código de autorregulación fija como horario de protección reforzada desde las 17.00 a las 20.00 horas, el espacio se prolongó al dirigirse especialmente a jóvenes de hasta 16 años. En este programa, Internet juega un papel muy importante ya que se busca la participación activa del público. Incluye Gomaespuminglish, que trata de enseñar inglés a los más pequeños con un tono humorístico y las series para jóvenes: Las chicas de Gilmore, Buffy Cazavampiros y La Guerra en Casa. 


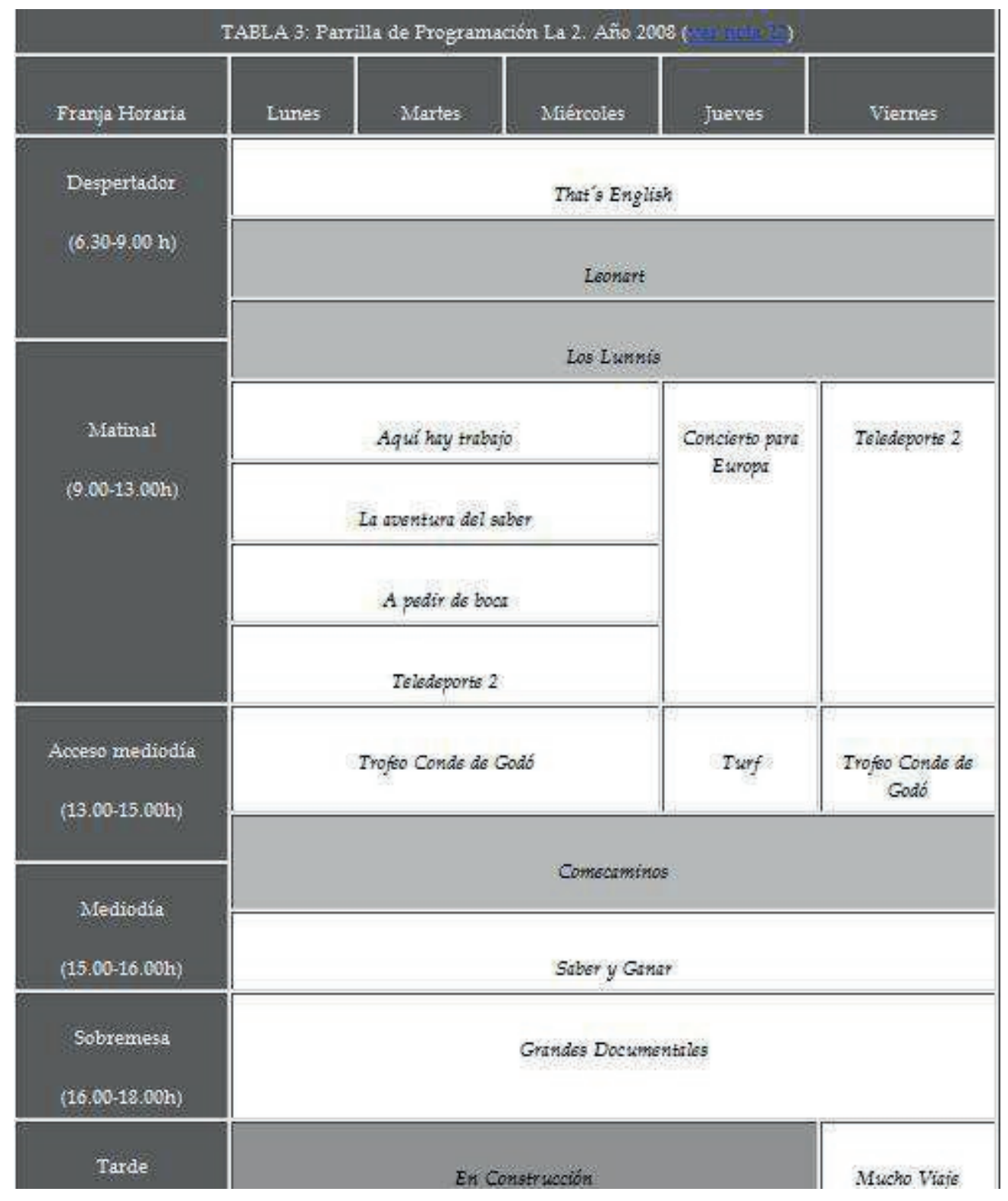

Mientras la $2^{\text {a }}$ Cadena de TVE programó espacios también dedicados a un público juvenil, los demás canales emitieron en este mismo horario una oferta dirigida a un target adulto basada en el factor entretenimiento. TVE emitió en la semana analizada la novela Marina y el espacio de actualidad España Directo. Antena 3 emitió también una telenovela, Pura Sangre, el concurso ¿Quieres ser millonario?, y el talk show, El diario de Patricia. Cuatro emitió la serie Embrujadas y los concursos El Gran Quiz y Alta Tensión. Telecinco programó el magazine Está pasando y el concurso 
Pasapalabra. Y por último, en la Sexta se pudo ver las series Me llamo Earl, Prision Break, Navy CIS y JAG: alerta roja.

\subsection{Código PAOS}

Teniendo en cuenta que la oferta de La 2 en 2008 para los más pequeños en la franja de protección reforzada de la infancia estaba constituida por Los Lunnis (el mediodía no entra dentro de esta consideración y las tardes se orientan más a los jóvenes), se ha seleccionado como objeto de estudio un corte publicitario realizado durante la emisión de este espacio. De este modo, se ha analizado la publicidad emitida el miércoles 30 de abril de 2008.

Desde las 7 de la mañana programó el espacio Leonart. A las 7.30 comenzaron Los Lunnis sin realizar una pausa publicitaria. Por lo que el primer bloque de spots que se emitió en la franja de protección especial (de 8 a 9 de la mañana) fue el que separó la sección protagonizada por los personajes de Los Lunnis y la siguiente serie que compone el contenedor, Clifford, el gran perro rojo, que comenzó a las 7.50 horas.

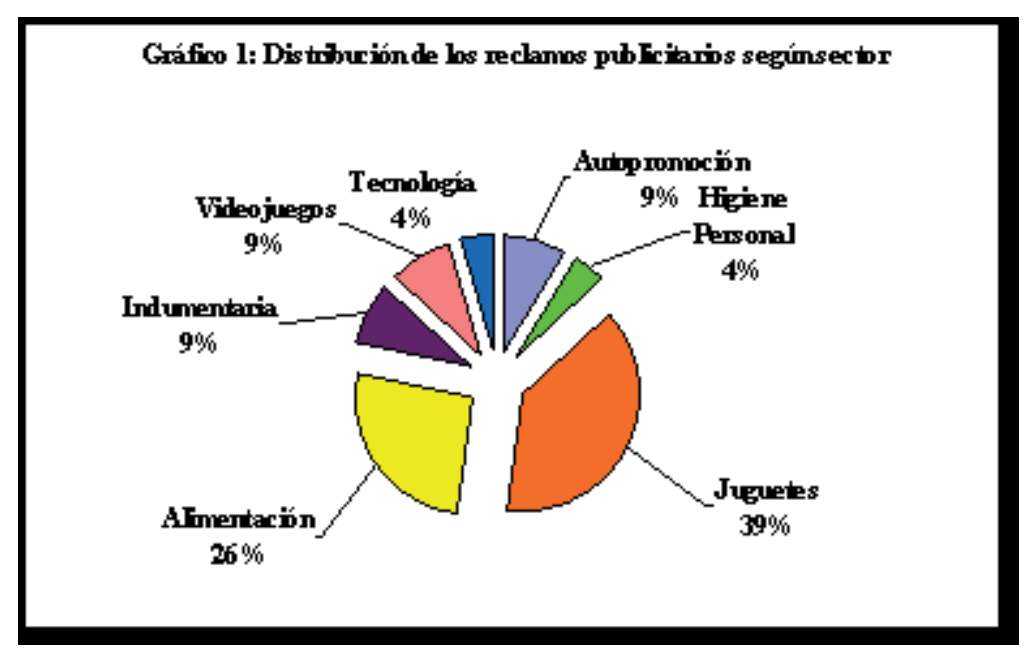


Esta pausa publicitaria tuvo una duración aproximada de cuatro minutos tras casi una hora de programación ininterrumpida y se distinguieron reclamos de siete categorías diferentes: juguetes, autopromoción, higiene personal, alimentación, indumentaria, videojuegos y tecnología. Se emitieron dos anuncios correspondientes a autopromoción de Televisión Española. Una de ellas hacía referencia al Gran Premio de Motociclismo retransmitido por La Primera y el otro, al Premio de Baloncesto que se podría ver en La 2. El resto de reclamos se dirigían a niños y adolescentes pero principalmente, al target infantil.

Tal y como se aprecia en el gráfico 1, el 40\% de los anuncios emitidos durante este bloque en horario de protección reforzado de la infancia hacía referencia a juguetes. El segundo gran sector del cuál más productos se anunciaron fue el de la alimentación. El 26\% de los reclamos eran de alimentos y bebidas, lo cuál representa un alto porcentaje sobre la reducida promoción de otros sectores como la tecnología o la higiene personal que constituyen un $4 \%$ de los anuncios emitidos.

En el bloque analizado se promocionaron galletas, cereales y cacao. Curiosamente, el anuncio de las galletas Arluy Choco recurre al personaje ficticio "El monstruo de las Galletas", conocido por la mayoría de los niños, por lo que es un gancho atractivo para este público. Por otro lado, una voz en off cita que Arluy son las galletas saludables para los niños y en una sobreimpresión aparece el eslogan: Arluy cuida de ti. Una parte, claramente dirigida a los padres.

Por otro lado, el spot de Corn Flakes de Cuétara, una mezcla de cereales y chocolate, contiene ciertos elementos que pueden resultar agresivos para los niños de edades más tempranas. El protagonista del anuncio es un cereal que salta desde una estantería colgado del ojo de un oso de peluche y al que le dice: "No me mires así que 
no te pienso dar". De hecho, el eslogan de la marca para anunciar estos cereales cubiertos de galleta y chocolate es: Los cereales más bestias.

Las otras dos marcas presentes en este bloque publicitario son Nesquik y Cola Cao. Por un lado, Cola Cao anuncia el batido Cola Cao Energy, que tiene la ventaja diferencial de que uno se lo puede llevar a donde quiera. Así, el spot lo protagonizan unos niños de unos catorce años que están jugando al baloncesto sobre una colchoneta y que tiene por eslogan: Te lo tomas donde quieres. En este caso, se trata de un reclamo que refleja hábitos de vida saludables ya que los protagonistas están practicando deporte y en vez de tomarse un refresco deciden tomar un batido de Cola Cao. El otro spot de la marca lleva una mayor carga comercial. Lo que se promociona son los regalos que los consumidores pueden poseer al adquirir los estuches grandes de la marca. Se trata de unos "Air Futbol" de los protagonistas de la serie de dibujos animados Oliver y Benji. Por lo que la estrategia de marketing de usar un personaje afín con el público objetivo es evidente ya que, muchos de los niños pueden sentirse atraídos por el producto no por sus nutrientes o sabor, sino por el juguete que regala.

Por último, Nesquik promociona el cacao soluble de siempre con un fuerte mensaje persuasivo: ¿Estás listo? Pásate a Nesquik. Es un anuncio que pretende robar clientes a su principal competidor, Cola Cao. Atendiendo a la tipología que establece Barrio García de publicidad comparativa, el anuncio de Nesquik responde a un tipo de comunicación comercial en la que el competidor no es mostrado ni tampoco es nombrado, pero se intuye, pues la otra principal marca de cacao soluble del mercado es Cola Cao (Barrio, 2001: 10). El reclamo puede vulnerar la capacidad de los niños para tomar decisiones de compra juiciosas e independientes pues, existe una fuerte presión de venta implícita en el mensaje: Pásate a Nesquik. 
El otro spot de la marca pertenece al nuevo helado Nequik Go. En el spot se ve a un grupo de niños que van en bicicleta por el parque y en el que el mensaje del anunciante es cantado: "... en el quiosco de helados me lo pido, es mi helado preferido". Al mismo tiempo, en una sobreimpresión en grande se hace referencia a que es una fuente de calcio. Al igual que en el anuncio de Cola Cao los niños están practicando deporte, lo que refleja un estilo de vida saludable. Se trata de vender que es sano porque contiene calcio, algo que es un argumento de venta dirigido a las madres ya que, los niños, sobre todo, los de menor edad, difícilmente lo comprenderán. Asimismo, la marca cumple con la norma contemplada en el Código PAOS sobre seguridad ya que, los niños que aparecen montando en bicicleta llevan puestos los cascos y rodilleras (ver nota 23).

En definitiva, se puede concluir que La 2 cumple con la normativa recogida en la Directiva Televisión Sin Fronteras que hace referencia a que no se harán interrupciones publicitarias durante los programas infantiles cuya duración sea inferior a 30 minutos. Sin embargo, no respeta el compromiso recogido en el Código de Autorregulación de Contenidos Televisivos e Infancia de favorecer la identificación de los programas mediante algún tipo de logotipo o símbolo.

Tan sólo con el análisis de un corte publicitario se puede deducir que, aunque se han extremado las precauciones a la hora de hacer publicidad de alimentos dirigida a niños, se siguen promocionando en gran medida. En el caso de la $2^{a}$ Cadena de TVE es el segundo sector con mayor presencia después de los anuncios de juguetes. Además, se observa una nueva tendencia en los anuncios de alimentos dirigidos a los niños. Una parte de los reclamos se encamina a atraer a que el niño seleccione ese producto a través de técnicas comerciales como promocionar algún juguete de regalo o incluir en la publicidad a algún personaje de su confianza, con cuidado de que éste no incite directamente al consumo. $\mathrm{Y}$ en una segunda parte del anuncio, se trata de 
ganar la confianza de los padres como compradores finales. Algo que se hace al mencionar las cualidades saludables y beneficiosas que ese producto tiene para la salud y difíciles de descifrar y de constituir la ventaja competitiva para los más pequeños.

Como ejemplo de esta nueva estética puede señalarse la nueva campaña de los bollos DooWap de la Bella Easo (ver nota 24). Tomando con referencia el anuncio impreso de esta marca (ver nota 25), se aprecia la imagen de una madre que está comiendo el producto ante la atenta mirada de su hija. El eslogan de la marca es: ENCANTA a los niños, DA CONFIANZA a las madres. Además, la parte inferior del anuncio contiene una parte explicativa: "DooWap da CONFIANZA a las madres porque sus productos están elaborados: sin grasas hidrogenadas, sin conservantes, sin colorantes. A los niños les ENCANTA porque están buenísimos, les aporta toda la energía que necesitan para jugar, estudiar y sobre todo, querer a sus madres":

Se puede decir que el anuncio está más dirigido a convencer a las madres que a los niños. Además, a pesar de todas estas ventajas que se mencionan, no se hace referencia a las calorías que cada uno de estos bollos contiene aunque sí hace referencia a que aportan energía para las actividades diarias como estudiar y jugar. Aunque se prescinde de hacer alusiones directas al deporte como por ejemplo, sí sucede en los spots de Cola Cao o Nesquik, se deduce que es un alimento indicado para llevar a cabo actividades y no cuando se tiene una vida sedentaria.

\section{Conclusiones}

A pesar del peso que la industria de alimentos y bebidas tiene sobre la inversión publicitaria, a la vista de los resultados arrojados por Autocontrol parece que en 
nuestro país se ha tomado conciencia del problema y se cumple eficazmente la aplicación de normas éticas fijadas en el Código PAOS.

No puede indicarse lo mismo sobre la regulación de contenidos televisivos dirigidos a niños ya que, actualmente, y teniendo en cuenta los datos de la Asociación para la Autorregulación de la Comunicación Comercial y de la Comisión Mixta de Seguimiento del Código, las cadenas generalistas españolas destacan por su falta de compromiso. Asimismo, el estudio de las parrillas de programación demuestra que los programas infantiles y juveniles se han ido eliminando a excepción, como ya se ha destacado, de la $2^{\text {a }}$ Cadena de TVE, que presenta una oferta variada de lunes a viernes.

Por otro lado, deben señalarse algunos inconvenientes que se aprecian en el Código de Autorregulación de Contenidos Televisivos e Infancia y que tienen como consecuencia la falta de adecuación entre las necesidades de los operadores televisivos y las audiencias. Por ejemplo, muchos colegios suelen tener un horario intensivo y los niños se quedan a comer en el colegio pero, también hay muchos otros que comen en sus hogares y aprovechan el tiempo de descanso para ver la televisión. Lo cuál se refleja en la decisión de La 2 de programar contenidos infantiles en este horario y que sin embargo, no se recoge entre las franjas de protección reforzada que establece el Código. Esto origina el consumo de productos aparentemente destinados a un público infantil pero que, por su contenido, no resultan apropiadas para este segmento de edad, como es el caso de las series de animación americanas Los Simpson y Padre de Familia. Además, durante los fines de semana sólo contempla como franjas de protección especial las mañanas a pesar de que los niños también suelen estar presentes por las tardes. 
Otra contrariedad que puede señalarse es que la Comisión Mixta de Seguimiento del Código elabora el Informe de Seguimiento a raíz de las quejas recibidas, lo que deja fuera los incumplimientos no denunciados. Pero que no se reciban reclamaciones no necesariamente significa que las cadenas cumplan el horario de protección reforzada de la infancia. Algo que refleja el estudio independiente que realiza la Asociación de Telespectadores y Radioyentes en colaboración con el Centro Universitario Villanueva (ver nota 26).

Por último, en cuanto al problema de obesidad y sobrepeso existentes, debe destacarse que para erradicar el fomento de malos hábitos y valores sociales y culturales inadecuados entre los más pequeños no sólo se debería ejercer una fuerte presión y control sobre la publicidad, sino que también se debería cuidar más e incentivar la emisión de programas televisivos educativos y aptos para ser consumidos por menores, pues es evidente la gran influencia que este medio ejerce sobre el público infantil.

Como ya se ha comentado, se identifica una publicidad de alimentos infantiles con dos argumentos de venta: uno destinado a los consumidores (los niños) y el otro, dirigido a los compradores (los padres). De este modo, los anuncios reflejan la preocupación actual imperante en la sociedad. Pues combinan la idea de fomentar estilos de vida saludables (como la realización de actividad física en los spots de Nesquik y Cola Cao) con técnicas de marketing atractivas para los niños (como regalos promocionales tales como los "Air Futbol" que se obsequian con los estuches grandes de Cola Cao) cuya presión comercial choca con la racionalidad de los niños en cuanto a toma de decisiones.

En cuanto al Código PAOS, también pueden señalarse alguna carencia pues establece que, en función de la edad que tengan los destinatarios de la publicidad, la 
responsabilidad que de esta se desprende y la infracción del código será mayor o menor. Sin embargo, existen anuncios que aunque están dirigidos a un público adulto, el infantil también es susceptible de percibirlo y de desear consumir el citado producto, no por sus características sino, por el hecho de que es degustado por un personaje conocido o con un alto poder presciptor.

Debería aprovecharse la influencia que los contenidos audiovisuales ejercen sobre los niños y los horarios en los que ellos se encuentran frente al televisor para fomentar la práctica de ejercicio, la comida sana y dar indicaciones sanitarias como, por ejemplo, consumir frutas y hortalizas y beber mucha agua pues, la educación en materia de nutrición y salud es crucial para prevenir el sobrepeso y la obesidad. La acción coordinada de estas dos fuentes de comunicación, la publicad y la televisión, puede ejercer un efecto positivo en la educación de los más pequeños si se emplea de modo responsable.

\section{Bibliografía}

Libros:

CORTÉS, José Ángel: La estrategia de la seducción. La programación en la neotelevisión. Pamplona, 2001. Ediciones Universidad de Navarra.

FERNÁNDEZ AREAL, Manuel: Conceptos básicos para una buena decisión. Pontevedra, 2000. Diputación de Pontevedra.

RAMOS FERNÁNDEZ, Fernando: La publicidad contaminada. Los consumidores ante la autorregulación publicitaria. Madrid, 2003.Editorial Universitas, S.A. 
TUR VIÑES, Victoria: Comunicación publicitaria de juguetes en televisión. Alicante, 2004. Publicaciones Universidad de Alicante.

VV.AA.: La publicidad en televisión. V Jornadas de Comunicación Social, Pontevedra, del 30 de septiembre al 2 de octubre de 1998. Pontevedra, 1999. Diputación de Pontevedra.

Fuentes Hemerográficas:

Diario El Mundo. Domingo, 19 de noviembre de 2006.

Diario El País. Del 11 al 17 de junio de 2007.

Revista XL Semanal. TvMás. Del 16 al 22 de mayo de 2008 y del 2 al 8 de mayo de 2008.

Revista TP. De 11 al 17 de junio de 2007 y del 28 de abril al 4 de mayo de 2008.

Revista IPMARK 697. Del 16 al 31 de marzo de 2008.

Revista El Publicista No 181.

Publicaciones:

AIMC: Resumen Estudio General de Medios. Abril 2007-marzo 2008. Disponible en: www.aimc.es. Consultado el 15 de mayo de 2009.

DEL RÍO ÁLVAREZ, Miguel; ROMÁN BLAS, Mariano (eds.): Programación Infantil de Televisión: Orientaciones y Contenidos prioritarios. Madrid, 2005. Instituto Oficial 
de Radio y Televisión (IORTV). Disponible en: www.rtve.es. Consultado el 23 de abril de 2009.

EIAA (European Interactive Advertising Association- Asociación Europea de Publicidad Interactiva): Cambio de tendencias. Internet ya rivaliza con la televisión en consumo de medios. 14 de noviembre de 2007. Disponible en: http:/ / www.eiaa.net. Consultado el 23 de abril de 2009.

INSTITUTO OFICIAL DE RADIO Y TELEVISIÓN: Corporación RTVE. Principios básicos de la programación. Madrid, 2007. Consejo de Administración de RTVE.

Webgrafía:

www.autocontrol.es www.formulatv.com www.ocu.org

www.aspec.org.pe/ www.tvinfancia.es www.consumer.es

www.rtve.es www.atr.org.es www.diabetesvoice.org/es

WwW.msc.es

Otras referencias

Acuerdo FIAB (Federación de Industrias de Alimentación y Bebidas). Consultado el 15 de mayo de 2009. Madrid, 9 de junio de 20005. Disponible en www.autocontrol.es. Consultado el 15 de mayo de 2009. 
Código de Autorregulación sobre Contenidos Televisivos e Infancia. Madrid, 9 de diciembre de 2004. Disponible en www.tvinfancia.es. Consultado el 15 de mayo de 2009.

Código PAOS (Código de Autorregulación de la Publicidad de Alimentos dirigida a menores, prevención de obesidad y salud). 29 de marzo de 2005. Disponible en www.autocontrol.es. Consultado el 15 de mayo de 2009.

Constitución Española de 27 de diciembre de 1978. Madrid, 2003. Boletín Oficial del Estado. Ministerio de la Presidencia.

Directiva 2007/65/CE del Parlamento Europeo y del Consejo de 11 de diciembre de 2007 por la que se modifica la Directiva 89/552/CEE del Consejo sobre la coordinación de determinadas disposiciones legales, reglamentarias y administrativas de los Estados miembros relativas al ejercicio de la radiodifusión televisiva. Diario Oficial de la Unión Europea, 18 de diciembre de 2007, pp. L332/27L332/45.

Dossier de prensa "La 2 se mueve". Gabinete de Prensa de RTVE. Viernes, 13 de abril de 2007. Disponible en: www.rtve.es. Consultado el 23 de abril de 2009.

Ley 17/2006, de 5 de junio, de la radio y televisión de titularidad estatal. Boletín Oficial de Estado, 6 de junio de 2006, núm. 134, p. 21207. Disponible en: www.rtve.es. Consultado el 23 de abril de 2009. 


\section{Notas}

Nota 1: Constitución Española de 27 de diciembre de 1978. Madrid, 2003. Boletín Oficial del Estado. Ministerio de la Presidencia. Págs. 12-13.

Nota 2: Acuerdo sobre la Autorregulación de la Publicidad de Alimentos y Bebidas dirigidas a menores entre el Ministerio de Sanidad y Consumo (MSC), la Federación Española de Industrias de Alimentación y Bebidas (FIAB) y La Asociación para la Autorregulación de la Comunicación Comercial (Autocontrol). Madrid, del 9 de junio de 2005. Pág.2. Disponible en: www.autocontrol.es (códigos y acuerdos).

Nota 3: Disponible en: www.autocontrol.es (códigos sectoriales)

Nota 4: Directiva 2007/65/CE del Parlamento Europeo y del Consejo de 11 de diciembre de 2007. Diario Oficial de la Unión Europea, 18 de diciembre de 2007, pp. L332/27-L332/45.

Nota 5: Pág. L332/40.

Nota 6: Pág. 332/43.

Nota 7: Este Código se desarrolla en el siguiente punto.

Nota 8: D.M: Obsesión por el público infantil. En: Revista El Publicista, nº 181. Págs. 24 y 25 .

Nota 9: En diciembre de 2006 Autocontrol lanzó una campaña de autopromoción para darse a conocer como organismos útil y mediador entre la industria publicitaria 
y los consumidores. Ver: AUTOCONTROL: Autocontrol presenta su primera campaña de publicidad. En: Noticias Boletín, $n^{\circ}$ 115. Enero de 2007. Disponible en: www.autocontrol.es (sala de prensa).

Nota 10: AUTOCONTROL: La Comisión de Seguimiento del Código PAOS analiza el Informe de Resultados. En: Noticias Boletín, n ${ }^{\circ}$ 127. Febrero de 2008. Ver: www.autocontrol.es/bbddaap/noti/2008/no080203.pdf

Nota 11: DEL RÍO ÁLVAREZ, Miguel; ROMÁN BLAS, Mariano (eds.): Programación Infantil de Televisión: Orientaciones y Contenidos prioritarios. Madrid, 2005. Instituto Oficial de Radio y Televisión (IORTV). Pág. 16.

Nota 12: Ley 17/2006, de 5 de junio, de la radio y televisión de titularidad estatal. BOE N ${ }^{\circ} 134$.

Nota 13: Disponible en: www.tvinfancia.es

Nota 14: AIMC: Resumen Estudio General de Medios. Abril 2007- marzo 2008.

Nota 15: COMISIÓN MIXTA DE SEGUIMIENTO: Segundo Informe de Evaluación sobre la Aplicación del Código de Autorregulación de Contenidos Televisivo. 31 de julio de 2007.

Nota 16: ALJARILLA, Elena: La Unión Europea cierra filas junto a los anunciantes y a las cadenas de televisión. En: Diario El Mundo. Domingo, 19 de noviembre de 2006. Página 76. 
Nota 17: MAS, Fernando: Reino Unido prohíbe los anuncios de comida basura en horario infantil. En: Diario El Mundo. Domingo, 19 de noviembre de 2006. Página 76.

Nota 18: Una de las principales características del Código de Autorregulación sobre Contenidos Televisivos e Infancia es la incidencia en la necesidad de diferenciar entre el público infantil y juvenil y evitar la ambigüedad del concepto "menores". La audiencia infantil es la más vulnerable y está formada por los niños menores de 13 años.

Nota 19: CORTÉS, José Ángel: La estrategia de la seducción. La programación en la neotelevisión. Pamplona, 2001.Ediciones Universidad de Navarra. Pág. 131.

Nota 20: Revista TP N ${ }^{\circ}$ 2.195. Del Lunes 28 de abril al domingo 4 de mayo de 2008.

Nota 21: Para la programación de 2007 se toma como referencia la programación del lunes 11 al domingo 17 de junio de 2007. Fuentes: Revista TP N ${ }^{\circ} 2149$ y diario El País correspondiente a esas fechas.

Nota 22: Revista TP N ${ }^{\circ}$ 2.195. Del Lunes 28 de abril al domingo 4 de mayo de 2008.

Nota 23: La décima norma ética que recoge el Código PAOS se refiere al concepto de seguridad. Se expone que cuando en la publicidad de alimentos o bebidas se incluyan prácticas deportivas, las personas que aparezcan realizando tales actividades deberán ir provistas del correspondiente equipo de seguridad.

Nota 24: Spot emitido el martes, 5 de junio de 2008 en La 2. Se insertó durante una pausa publicitaria del espacio juvenil En Construcción, a las 19.50 horas y por la tanto, todavía dentro de la franja de protección reforzada de la infancia. 
Nota 25: Anuncio publicado en diario gratuito Metro. Jueves, 5 de junio de 2008.

Nota 26: Ver: http:// www.atr.org.es 